\title{
The myth of the "Culture code" in economic research is $^{\text {is }}$
}

\author{
Vitaly Tambovtsev \\ Lomonosov Moscow State University, Moscow, Russia
}

\begin{abstract}
This paper is devoted to the critical analysis of today's mainstream approach to the inclusion of the factor of culture in economic research. National culture is treated in this framework as a reified entity measured by societal values and is persistently included as a "culture code" throughout different contexts. The paper presents evidence contradicting this treatment, and an alternative methodology for economic analysis of cultural phenomena is suggested, namely that each mass cultural practice should be analyzed on a "case-by-case" basis, comparing stakeholders' costs and benefits.

(C) 2015 Non-profit partnership "Voprosy Ekonomiki”. Hosting by Elsevier B.V. All rights reserved.
\end{abstract}

JEL classification: E02, O17, O43, Z10.

Keywords: culture, economic growth, culture code, reification, societal values, cultural practices.

\section{Introduction}

With the world economy beginning to recover from the crisis, understanding the reasons for and the sources of growth, development and modernization has gained vital importance. The recession has highlighted the heterogeneity of the world economy and the diversity of reactions to change across countries. In some countries, the governments accepted the crisis as yet another manifestation of "creative destruction," as an incentive to seek new approaches and capture new opportunities. In other countries, eyes were fixed on the "glorious past," and attempts were made to find the external enemies who had caused the downturn and to restore everything back to "the way it was." Meanwhile, their own economic policies, which often aggravated the negative impact of changes in

\footnotetext{
t The updated English version of the article published in Russian in Voprosy Ekonomiki, 2015, No. 12, pp. 85-106. E-mail address: vitalytambovtsev@gmail.com.

Peer review under responsibility of Voprosy Ekonomiki.
} 
the global economy, were declared perfectly fit and sound and in no need of any changes due to intrinsic reasons.

The classical theory of economic growth, rooted in the works of Adam Smith and David Ricardo, named three main growth factors, namely labor, capital (investments), and land (natural resources). ${ }^{1}$ the original set of factors was later expanded to include technology (Romer, 1986), institutions (Rodrik et al., 2004; Robinson et al., 2005), and culture (Licht et al., 2007).

It is the latter factor that is now interpreted by a number of researchers, writers and statesmen in Russia as the ultimate cause of the fundamental differences between the Russian economy and others. They stress the distinct nature of the Russian culture and the presence of a deeply rooted "culture code" within it that has remained unchanged for centuries and cannot be altered without the loss of national identity. From their point of view, Russia's "culture code" renders futile, and even harmful, any attempts in this country to apply any economic policy approaches and measures that have driven growth, development and modernization in a large number of other economies.

We have put aside the purely ideological aspect of the so-called "civilizational approach" and have instead focused on the scientific (theoretical and empirical) arguments in favor of the decisive influence of national culture on economic growth and development, and on the counterarguments stressing that culture - along with many other factors-does indeed influence the economy, but does not predetermine its traits. In the following two sections, we will examine today's prevailing, reified interpretation of national culture as a system of values and the role of the culture code as a mechanism that ensures its stability. We have also critically reviewed the application of this interpretation in economic analysis. In the fourth section, we will describe some facts that contradict this prevailing concept, and in the fifth section, we provide a brief description of alternative (holistic rather than value-based) interpretations of culture. The sixth section addresses the concept of culture as a popular practice and the resulting methodology of including the cultural factor in economic surveys. The final section contains general conclusions from our analysis.

\section{Culture as a system of values. Measuring and using culture in economic analysis}

The concept of culture, although widely used across various branches of the social sciences, lacks a generally accepted definition. Whereas Alfred Kroeber and Clyde Kluckhohn (1952) found 164 definitions of culture in the mid-20th century, in the early 21 st century, the number of definitions is now well in excess of 500 (Kravchenko, 2000, p. 271). Up until the early 1980s, applied economic research had almost completely ignored the phenomenon of culture as an explaining or explained factor. The reason is quite obviously the lack of a sufficiently massive volume of data obtained via more or less valid measures. The situation changed after a publication by Geert Hofstede (1980), who not only suggested operationalizing culture as a system of societal values but also completed a comprehen-

\footnotetext{
1 The perception of natural resources as a pillar of economic growth was shaken by Jeffrey Sachs and Andrew Warner (Sachs, Warner, 1995).
} 
sive international survey that provided a basis for the dimensions of national culture and enabled quantitative comparisons between countries. During the later period, the value-based understanding of (national) culture became almost universally accepted. Culture measurement efforts were enhanced with new international projects that began to accumulate large statistical databases (Inglehart et al., 2004; Schmitt et al., 1993; House et al., 2001). In our opinion, the general acceptance of Hofstede's approach by researchers is primarily because it enables a transition from a purely qualitative to a quantitative analysis of the relationships between culture and other domains of economic, social and political life.

Hofstede interpreted culture as the "collective programming of the mind which distinguishes the members of one group or category of people from another" (Hofstede, 1991, p. 4). This programming is carried out through socializing members of a group and raising them under a certain system of values defined as "broad tendencies to prefer certain states of affairs over others" and which form the "key element of culture" (Hofstede, 1991, p. 35). At the same time, Hofstede himself drew a distinct line between individual and societal values, characteristic of a group (category) as a whole that distinguish it from others: "There is hardly an individual who answers each question exactly by the mean score of his or her group: the 'average person' from a country does not exist" (Hofstede, 1991, p. 253).

Accordingly, societal culture is seen as a statistical average based on individual "broad tendencies" to prefer certain situations over others, but identified through forming and interpreting clusters ("dimensions" of culture). Having processed several tens of thousands of individual responses, Hofstede identified five dimensions of societal cultures:

- power distance (PDI) (high/low);

- uncertainty avoidance (UAI) (high/low);

- individualism/collectivism (IDV);

- masculinity/femininity (MAS);

- long-term orientation (LTO) (high/low).

Authors of alternative measurement systems for societal cultures are moving in the same direction, though their use of different primary questionnaires yields other "dimensions" of cultures at the level of national (country) societies. "The common method for measuring psychological constructs is to ask individuals to provide self-reports on their attitudes, values, or behaviors. When averaging these reports, we will get an estimate of the average level of that particular psychological construct within the chosen group" (Fischer, 2006, p. 1420). The general acceptance of this approach, however, does not eliminate significant problems that arise when attempts are made to interpret the aforementioned statistical averages (and more complex ones, such as clusters, principal components, etc.) as characteristic of some entities, existing independently apart from the individuals whose estimates and judgments are reflected in the initial measurements.

The main methodological problem is connected to the high sensitivity of averages to source data. This may lead to a situation where the interpretation of the economic calculations using them as variables would be heavily dependent on the sampling parameters underlying those averages. Here are some examples of this problem. 
The first example addresses the conclusions made by Ronald Inglehart and his colleagues (Granato et al., 1996), who analyzed the connection between "materialistic" and "post-materialistic" values and economic growth. Based on a sample of 25 countries, they showed that the cultural attitudes of achievement ${ }^{2}$ and thrift have a positive impact on economic growth, whereas prioritization on "post-materialistic" values has a negative impact in the long term. However, later calculations by Edwards and Patterson (2009) and Hanson (2009) showed that these relations and impacts are sensitive to the sample composition as well as to the time period in question, i.e., they actually represent artifacts rather than real dependencies.

The second example also addresses studies by Inglehart and his colleague Christian Welzel (Inglehart and Welzel, 2006). Their theory of consistent human development, which became highly popular among modernization theorists and statesmen, asserts the precedence of economic development, which leads to cultural changes, i.e., changes in the system of values that, in turn, enable the democratization of a society. The authors base their logic on a statistical analysis of relevant data from countries representing $85 \%$ of the world population. However, a later analysis of practically the same data, conducted by Victoria Spaiser et al. (2014), who used their own new approach that they called "Bayesian Dynamic Systems" (Ranganathan et al., 2014), revealed a different sequence of changes, i.e., human rights protection and democratization precede the rise in the relevance of emancipation values, such as personal autonomy and gender equality. Moreover, research has shown that, following the development of human potential in a country, the first thing to increase is the level of democratization, followed by emancipation (individual freedoms). These changes only occur after the Human Development Index (HDI) has exceeded a certain threshold. The analysis also showed that a higher level of emancipation sets a wealth growth limit for a society; i.e., after reaching a high level of democratization and freedom, societies seem to look for a certain equilibrium that would not support further economic growth.

It should be stressed that the two examples above are not there to prove Inglehart's concepts wrong but to demonstrate that the use of average statistical characteristics of societal cultures in econometric macro-analysis requires careful attention to the research methodology, including the choice of variables (culture measures) and processing techniques.

The third example is an illustration of this requirement. Judit Kapas (2014), noticing the unsatisfactory results from measuring culture based on the level of generalized trust ${ }^{3}$, studied the relationship between individual values and economic development based on data from the Schwartz Values Survey. A multi-country analysis revealed that the individual values measured according to Schwartz have

\footnotetext{
${ }^{2}$ Attention was drawn to the relationship between "achievement motivation" and economic growth in a book by David McClelland (1961), though its appealing conclusions failed to demonstrate empirical proof (Beugelsdijk and Smeets, 2008).

3 This sounds perfectly plausible because the level of generalized trust in a country is determined primarily by the quality of formal institutions, as demonstrated by a number of empirical studies (Beugelsdijk, 2006; Rothstein, Stolle, 2008; Herreros, 2012). Consequently, generalized trust cannot serve as a suitable dimension of culture and/or informal institutions existing in a country, but is used as such nonetheless (see Tabellini, 2010; Williamson, 2009, and others).
} 
no impact on economic development, provided that the quality of formal institutions is controlled. This differs from the results obtained for different value indicators (the cultural index built around Inglehart's World Values Survey measures and a different level of individualism, measured according to Hofstede), which suggest that values do have an impact on economic development.

As we can see, finding a solution to the key problem of the entire branch of macro-analysis of cultural impacts on economic development depends on which dimensions of culture are employed in econometric analysis.

\section{Reification of culture and the culture code}

The above problems, which arise when dimensions of societal culture are used in macroeconomic analysis ${ }^{4}$, are apparently rooted in the interpretation of culture that underlies those dimensions, as an independent entity existing apart from individuals.

Two approaches to understanding national culture have co-existed and competed ever since the dawn of scientific cultural research. One of them, dating back to Edward Tylor (1871) and Alfred Kroeber $(1917)^{5}$, viewed culture as a superorganic entity, coherent and holistic. The other, developed by Bronisław Malinowsky $(1926)^{6}$, treated culture as a sum of fragmented and controversial processes taking place in, and integrated into, a society. The first approach effectively means a reification of culture, deeming it to be a "thing" separate from human beings, endowed with its own substance and independent existence. The first approach has spawned a phenomenon in popular science called cultural determinism, which views culture as the driving factor behind most, if not all, social — and economic - processes. The second is built around culture as an essential part of human activity, deriving from it. Our study does not aim to analyze the development of these approaches, the arguments for and against them, etc., as those matters belong to anthropology and cultural science. We, on the other hand, are focused solely on the implications of adopting the views above in a methodology for studying the impact of national (societal) culture on economic processes.

The holistic concept of culture and the deterministic approach prevail in contemporary economic research (McSweeney, 2009; Taras et al., 2010). This seems to be the result of the general application of Hofstede's data and findings, or, rather, their explicit and implicit interpretation by his followers and opponents. ${ }^{7}$ In fact, Hofstede himself does not consider societal culture - as a system of values - to be separable from individuals, which is clearly revealed in the title of his article "Dimensions do not Exist...," where "dimensions" referred to the five cultural dimensions listed above (Hofstede, 2002). Nevertheless, according to a recent publication by Shalom

\footnotetext{
${ }^{4}$ Similar problems occur at the micro level, when cultural indicators are used in management research. Unfortunately, the format of this article does not allow us to dwell on this subject.

${ }^{5}$ Culture is "that complex whole which includes the knowledge, beliefs, arts, morals, law, customs, and any other capabilities and habits acquired by a human as a member of society" (Tylor, 1871, p. B; quote from Soares et al., 2007).

6 “...human cultural reality is not a consistent or logical scheme, but rather a seething mixture of conflicting principles” (Malinowski, 1926, p. 121; quote from McSweeney, 2009).

7 According to M. Morris, the reason why this approach is more common lies deeper. It is the "human brain's hardwired capacity for essentialism" (Morris, 2014, p. 14).
} 
Schwartz, societal culture is the "hypothetical, latent, normative value system that underlies and justifies the functioning of societal institutions. As such, culture is external to individuals" (Schwartz, 2014, p. 5) ${ }^{8}$.

Reified culture must be stable over time. Indeed, according to Hofstede, "cultures, especially national cultures, are extremely stable over time... Differences between national cultures at the end of the last century were already recognizable in the years 1900,1800 , and 1700, if not earlier. There is no reason they should not remain recognizable until at least 2100" (Hofstede, 2001, p. 34-36). The empirical evidence of this statement is, to say the least, controversial. The literature is actually abundant with evidence indicating that changes in societal cultures take quite a long time (see their review, e.g., in Schwartz, 2009, p. 3). At the same time, evidence of rather rapid changes in cultural values also exists (Fais, 2003; Drnáková, 2006, etc).

The holistic (civilizational) interpretation of culture invariably encounters the issue of identifying the sources of their stable nature and reproduction in time, as well as the origins of differentiation between cultures. ${ }^{9}$ Indeed, the behavior representative of a person's culture and the socio-economic environment in which that person acts are constantly undergoing change. The literature cites several such sources (and mechanisms): institutionalization (Zucker, 1977), i.e., the emergence of external enforcement mechanisms to ensure conformity with certain behavioral practices that were previously followed solely at the discretion of their subjects; imitation (Bryson, 2009), or individual training, made possible by the so-called "mirror neurons" in the human brain (Rizzolatti and Craighero, 2004); and the modular system of cognitive mechanisms "embedded" in the mind, allowing basic perceptions of the world, its design, etc. to be passed down through generations (Sperber and Hirschfeld, 2004). The reasons for differences between stable cultures can be found in the concept of multiple equilibria (Cohen, 2001).

In our opinion, the first of the above mechanisms is the most relevant, while the second and third, being based on the genetic traits of the human brain, perform a broader function than ensuring the lasting quality of cultures. Although the mechanism of institutionalization ${ }^{10}$ admits the concept of societal culture as a set of norms rather than a system of values, this fact does not diminish its explanatory role. Although the stability of social norms themselves has genetic (neural) roots (Buckholtz and Marois, 2012), an estimation of the (relative) stability of cultures fully relies on the (relative) stability of the norms.

This explanation, however - for some presumably ideological reason - is found unconvincing by a number of researchers who seek other bases of cultural stability. An analysis indicates that, in addition to explicit factors, there are im-

\footnotetext{
${ }^{8}$ It should be noted that Schwartz believed societal culture to be characterized primarily by values shared by the members of a society and by the level of value consensus between individuals (Schwartz, 2006; Schwartz and Sagie, 2000).

9 These are evidently not primary issues for the alternative, "process-based" interpretation because no borders are created between cultures, whereas cultural processes intersect and intertwine. According to this concept, in an aggregate cultural process, stable entities do not actually exist "on their own" but rather are defined by researchers (including amateurs, i.e., the very individuals who ponder on their differences from "others," forming their stereotypes of others which usually turn out to be inaccurate or simply incorrect see: Terracciano et al., 2005).

10 The term "institutionalization" is more characteristic of the language of social science than that of economic theory, which traditionally deals with the emergence or formation of institutions.
} 
plicit ones, which must be identified based on the context. The first group includes Kirdina's "institutional matrices $\mathrm{X}$ and $\mathrm{Y}$ "11; the second includes the concept of the "culture code".

It should be noted that the expression "culture code" has two different meanings, a semiotic and a journalistic one. The semiotic interpretation of culture code views it as a "'mesh' that culture 'throws over' the world to classify, categorize, structure and evaluate it" (Krasnykh, 2002, p. 232). In other words, a culture code is the knowledge of an individual derived from her being familiar with the phenomena of a culture, enabling her to interpret various external phenomena (natural as well as social) as signs conveying sense and meaning. Thus, in most Western countries, white color symbolizes purity, whereas in India it is the color of mourning. According to Abraham Moles, "we can call a 'code' anything that is known beforehand to both the sender and recipient of a message above the set of signs" (Moles, 1973, p. 130). Following from the above, a semiotic culture code is the overall knowledge of a group enabling (but not requiring) its members to interpret (understand) various things, qualities and relations as signs in a similar manner. Different culture codes explain the numerous cases of misunderstanding between people whose "background" knowledge does not match. It is easy to eliminate these misunderstandings through direct communication to enhance the knowledge of both parties. ${ }^{12}$

The second, journalistic sense of the term "culture code" is closest to the system of societal values, as seen from an analysis of related contexts. For example, the comment made by the Finmarket news agency concerning a study of the impact of values on the behavior of firms towards assuming risks (Finmarket, 2012; Mihet, 2012) was entitled "Russia's culture code hindering its modernization." Aleksey Verizhnikov, in reconstructing Russia's culture code based on pop song lyrics, though referring to the semiotic interpretation of culture code by Clotaire Rapaille (2006, p. 5), phrased his conclusions in terms close to Hofstede's dimensions (masculinity/femininity, delinquency/senility, hyperactivity/apathy) (Verizhnikov, 2008). In a dialogue between Andrey Konchalovsky and Alexander Auzan, the concept of culture code is also expressly connected to a set of basic values characteristic of a society (country) (Gusarova, 2015). ${ }^{13}$

However, if a culture code is just a doubling of the concept of societal culture, shouldn't it be the focus of attention? Should we speak about the myth of the "culture code," etc.? We believe we should because it is the culture code concept that best underlines two aspects of great theoretical and practical significance. The first is the decisive influence of culture on the course of almost any significant social, economic and political process in a country (nation). The second is the integrity and invariability of culture as a result of the invariability of its culture code. In other words, the concept of the culture code is a variation on the concepts of cultural determinism, which practically signifies the futility of any attempts to change the status quo, i.e., to "go against one's culture code."

\footnotetext{
11 A detailed critical review of Kirdina's approach is presented in an article by Bessonova (2007) and does not require a separate analysis here.

12 For a functional analysis of the semiotic culture code, see Enfield (2000).

13 An article by Maxim Trudolyubov (2013) contains a broader review of the journalistic usage of the term "culture code".
} 


\section{The integrity and decisive nature of societal culture?}

Recently, Alberto Alesina and Paola Giuliano conducted comprehensive research to implement the ideas of cultural determinism based on an extremely broad meaning of culture, identifying it with an aggregate of informal institutions (Alesina and Giuliano, 2014). A number of Russian scholars share a similar view (Yasin, 2007, 2014; Lebedeva, 2007; Lebedeva and Tatarko, 2009; Medvedeva and Medvedev, 2010; Auzan et al., 2011; Nifaeva and Nekhamkin, 2013).

However, if culture determines nearly everything in various societies, from the political system to the fine parameters of the financial sector, what determines the parameters of culture itself within a country? Although predetermining the opportunities and limitations of development in an economy, is any culture truly a homogeneous monolith that has an effect on people irrespective of their will and consciousness? Facts indicate the contrary.

Let's start with a bold thesis about the "clash of civilizations" advanced by Samuel Huntington (1993). The comprehensive statistical analysis of changes in the level of human rights protection in different civilizations, recently carried out by Wade Cole (2013), found little proof of this thesis, especially where it predicts an aggravation of social conflict related to Western human rights standards. The end of the Cold War also turned out to be of little significance for human rights protection practices in countries classified as representing different civilizations, which directly contradicts the arguments of Huntington. Based on data gathered between 1989 and 2007, from 20 countries representing 55\% of the world population, $\mathrm{Uz}$ (2015) demonstrated that although the gap between Western and non-Western cultures had indeed widened somewhat during that period, this did not mean that they were moving in opposite directions. Both moved in the same (Western!) direction. The speed of the one was merely faster than that of the others.

To what extent do societal cultures predetermine the values of the individuals "belonging" to them? There is empirical proof that country-specific "all-cultural" factors account for as little as $2 \%$ to $4 \%$ of the variance in individual values (Green et al., 2005; McSweeney, 2009 et al.), which is why it would be incorrect to argue that societal culture predetermines individual values. Ronald Fischer and Shalom Schwartz confirm this in their research demonstrating that individual values "associated with autonomy, relatedness, and competence show a universal pattern of high importance and high consensus [between individuals]" in all countries and cultures studied (Fischer and Schwartz, 2011, p. 1127). Studies by Charles Helwig (2006) point directly at the limited extent of cultural influence on individual development.

Moreover, an empirical analysis showed that the contrast of cultures as individualistic and collectivist, regarded as absolutely fundamental by most researchers and practitioners, is in fact misleading. Proceeding from the evolutionist concept of culture as a mechanism for adapting to the surrounding environment, Daphna Oyserman et al. (2002, p. 110) found that "depending on situational requirements, both individualism- and collectivism-focused strategies are adaptive; thus, it is likely that human minds have adapted to think both ways."

The inner heterogeneity of societal cultures can be seen in the example of different cities (Plaut et al., 2012) and regions within the same country (Talhelm et al., 2014). 
Important observations were made about the interaction between culture and business behavior. For example, Barry Gerhart demonstrated that most variations between corporate cultures are not explained by differences between national cultures as measured by Hofstede and the GLOBE indices (Gerhart, 2008a, 2008 b). A highly representative (as of 2005) review of research projects aimed at identifying the connections between characteristics of national cultures and variables describing different aspects of organizational behavior (Tsui et al., 2007) shows that no generalization has been achieved in this field so far. At the same time, the research that had been completed up to that point had identified a considerable number of special, local dependencies, which are undoubtedly of interest in the context of our article. Finally, we should not forget to mention the investigation into the correctness of identifying culture measured by societal values within the home country of the firm in question (Sawang et al., 2006). Having studied the behavior of employees at firms in Australia, Singapore and Sri Lanka, the authors came to the conclusion that a country (nation) and a set of societal values are not the same thing and cannot be treated as interchangeable in statistical analysis.

The results of empirical research (the number of papers in this field is much greater and we can only name a few) demonstrate quite unambiguously the following:

(a) national cultures are heterogeneous and cannot be considered as uniform, whole systems (of course, if we do not follow Schwartz in arguing that cultures exist independently from people); and

(b) their parameters (societal values) do influence but do not predetermine the behavior of individuals and firms.

With regards to a methodology for including culture as a factor in economic analysis, this means that the reified interpretation of culture, inherent in most research papers on the subject, is not the best measure for it. ${ }^{14}$ the occasional remarks by researchers that value-based dimensions of culture should be used because "they are simpler to measure" and because there are available databases are not convincing. Data about an individual's weight are undoubtedly easier to obtain than data about their IQ. Moreover, an individual's weight is an indirect reflection of his/her IQ because obesity does not generally suggest powerful intellect (except in the case of endocrine diseases). Nevertheless, no researcher ventures to use weight as a measure of intellect. On the practical side, it means that recommendations regarding which economic activities "correspond" to a country's culture and which do not (and thus should not be attempted) ${ }^{15}$ lack a scientific basis.

Thus, taking into account the heterogeneity of groups (particularly societies, national populations, etc.), using societal values to explain the behavior of particular individuals and firms within a country - because it is they, together with external factors, that predetermine the condition of an economy — would result

\footnotetext{
${ }_{14}$ An extensive critique of the value-based concept of societal culture is provided by Morris (2014).

15 The well-known conclusions by Hofstede provide an example: countries with masculine cultures have efficient mass production, heavy industry and base chemistry; countries with feminine cultures should engage in custom production, individualized services, agriculture and biochemical production; where the avoidance of uncertainty is not clearly manifested, innovations are bound to bring success, whereas high-precision production will prosper in areas where it is strong, etc. (Hofstede and Hofstede, 2005, p. 240).
} 
in the so-called "ecological fallacy" (Brewer and Venaik, 2014) of attributing statistical parameters and ratios existing at the level of a group to each element of that group.

Another important fact proving the irrelevance of the value-based interpretation of culture for economic analysis is that values do not directly influence behavior, as vividly illustrated through the famous natural experiment by Richard LaPiere (1934). The pattern "values $\rightarrow$ action," popular among social psychologists decades ago, has long since transformed, due to the efforts of many researchers, into a pattern easily comprehended by economists: "values $\rightarrow$ constraints $\rightarrow$ actions," whereby the phenomena serving as constraints vary across different models, from all types of norms (Cialdini et al., 1990) to the so-called self-efficacy, i.e., an individual's confidence that she has enough resources and abilities to achieve her objectives (Bandura, 1977). Societal culture (cultural context) is also one of the intermediaries between values and actions, constraining (and sometimes determining) various acceptable behaviors (Roccas and Sagiv, 2010). Accordingly, it comes as no surprise that even in areas such as religion, a coincidence of faith, beliefs, values and actual behavior is more the exception than the rule (Chaves, 2010).

\section{Alternative interpretations and dimensions of culture}

Our previous argument suggests that a reification and value-based measurement of culture prevents the cultural factor from being correctly included in economic analysis. This calls for outlining other concepts of culture.

Shinobu Kitayama has been a consistent critic of culture as an entity with values as key components. He noted that the generally accepted method of measuring culture and attitudes may register the situational reactions of respondents but not the deep structures of the conscious and subconscious. Accordingly, the assumption that a set of values identified in this way predetermines the behavior of individuals would be groundless. In Kitayama's opinion, a systemic concept of culture as "a dynamic system that is composed of many loosely organized, often causally connected elements - meanings, practices, and associated mental processes and responses" is more realistic (Kitayama, 2002, p. 92). Thus, a "system view of culture explicitly acknowledges that all psychological processes and mechanisms are potentially available for all peoples and cultures" (Kitayama, 2002, p. 93). ${ }^{16}$ Apparently, the systemic concept of culture effectively makes it similar to "enumerative" definitions, characterized by the intricacy of measurement, thereby preventing this concept from being employed in economic research.

As noted above, an alternative to the reified concept of culture can be found in the process-based concept, which is similar to enumerative interpretations in some respects, but different in that the process-based concept focuses on processes, i.e., sequences of actions, changes, etc. We will dwell on this concept in the final section of this article and will try to link it to the new methodology of including culture as a factor in economic analysis. In this section, we will consider other alternatives to the value-based measurement of national cultures.

\footnotetext{
${ }^{16}$ D. Oyserman et al. (2014) adopt a similar view, underlining the stochastic (rather than determinant) nature of relationships between cultural universals and behavioral actions.
} 
Social axioms approach suggested by Kwok Leung et al. (2002) is based on the assumption that cultures differ in how people perceive the structure of the world around them. Although values represent situations (states) evaluated as desirable or undesirable, social axioms represent relationships between an individual and the world, as well as those within the (social) world. An analysis of empirical data identified five generalized "dimensions" of this concept:

- social cynicism: either a negative or a positive attitude toward human nature;

- social complexity: certainty about either a single way or multiple ways to achieve something;

- reward for application: certainty (or lack thereof) that "life-long" hard work is rewarded;

- religiosity: either belief or disbelief in the existence of the supernatural;

- fate control: belief in either a predetermined nature of events in life or in the opportunity to define one's own trajectory in life.

An empirical analysis has shown that social axioms possess a considerable predictive ability, especially in situations where a future action depends on the subject's idea of how others would react to it (Kurman, 2011). That makes this approach similar to the concept of culture as an aggregate of descriptive norms (see below).

Each of the "dimensions" above consists of a number of "special" axioms, the list of which is not yet complete, as with the list of "dimensions" themselves. For example, quite recently a new social axiom, supported with empirical evidence, was proposed as a separate dimension, i.e., certainty that social relations are a zero-sum game where somebody's win invariably means somebody else's loss (Różycka-Tran et al., 2015). Evidently, the presence or absence of such certainty is potentially significant in all domains of life, from getting along with one's neighbors to international relations.

The scarcity of country-specific empirical data prevents (temporarily, we hope) the use of this approach in economic analysis. One should not make the ecological fallacy here, which is also true for any macro measurement of culture.

Tightness and looseness of culture. This approach, developed by Michele Gelfand et al. (2006), proposes evaluating national culture based on the rigidity of social norms and penalties for breaching them. This indicator is manifested at all levels, i.e., the society as a whole, various institutions and individual behavior, and has an impact on a broad spectrum of economic and social phenomena and processes. For example, it has been shown to have an effect on differences in understanding the phenomenon of leadership in various countries (Dickson et al., 2012), and the level of discretion in actions by company management (Crossland and Hambrick, 2011), etc. The only objection to this approach is that tightness and looseness do not so much characterize culture as they do the entire institutional environment of a country, including all of the laws and regulations introduced by the state. This raises doubts regarding the justification for combining the rigidity of the proper norms with the rigidity of enforcement mechanisms used to ensure obedience into a single characteristic: as experience shows (even in Russia), rigid norms may be followed selectively, i.e., not rigidly.

Culture as an aggregate of intersubjective perceptions. Unlike the two approaches above, this branch of cultural studies lacks integrity and even a common terminology. The general theme is an interpretation of culture as an aggregate of 
perceptions held by the "members" of a culture, concerning the values and beliefs prevailing in that culture. If those perceptions fit, they are considered "intersubjective" rather than individual. Chi-Yue Chiu et al. (2010, p. 482) defined intersubjective perceptions of culture as "beliefs and values that members of a culture perceived to be widespread in their culture." This definition stands very close to the concept of descriptive norms, i.e., the perception of members of a group about behaviors that, in their opinion ${ }^{17}$, are characteristic of (widely common among) its other members in various situations. This is how Fischer et al. (2009) suggest interpreting individualism/collectivism. The advantage of this understanding of culture is seen by its advocates in the formidable explanatory power of norms (Shteynberg et al., 2009), which is difficult to contest (Rimal and Real, 2003). However, the intersubjective approach faces at least two problems, i.e., how do "members" of a culture identify its other members and how (in what form and where) do intersubjective perceptions exist (Fischer, 2012). The lack of a convincing solution to these problems seems to preclude any discussions of future applications of this approach. The expansion of the concept of enhancing cultural values with norms (albeit in the twisted form of "intersubjective perceptions") is undoubtedly one of its strong points.

Thus, we have completed our brief overview of the non-value-based measurement of cultures as entities and will now move on to describing a fundamentally different understanding of national culture.

\section{Culture as a form of activity and economic analysis}

Probably one of the more general interpretations of culture is "any behaviour routinely acquired from conspecifics by non-genetic means. The qualifier 'routinely' implies that this is behavior shared by some significant subset of an adult population" (Bryson, 2009, p. 78).

As a mass phenomenon, non-genetically determined behavior also appears to be repetitive (in certain situations), which makes it resemble the notion of practice. In understanding the latter, we agree with Reckwitz (2002, p. 249), who argues that a practice is a "routinized type of behaviour which consists of several elements, interconnected to one other: forms of bodily activities, forms of mental activities, 'things' and their use, a background knowledge in the form of understanding, know-how, states of emotion and motivational knowledge."

The relevance of practices in research on social (including economic and political) processes was recently stressed by Christian Bueger (2014, p. 386), who highlighted the fact that they reflect both explicit and tacit knowledge possessed by individuals. This is why they are ontologically anterior to the various structural components of communities such as institutions, societal values, etc.

The understanding of culture as a common activity ${ }^{18}$ or as an aggregate of practices does not mean that culture is only about practices. By consciously or subconsciously processing the information they receive, the subjects of practices individuals - create certain generalizations, world models, social axioms, etc.:

\footnotetext{
17 Of course, this opinion may be incorrect (see Miller, McFarland, 1987).

18 By paraphrasing the name of an article by Øyvind Dahl (2014), we can say that culture is not what people have but what they do.
} 
"We view culture as a socially interactive process of construction comprising two main components: shared activity (cultural practices) and shared meaning (cultural interpretation). Both components of cultural processes are cumulative in nature since they occur between, as well as within, generations" (Greenfield et al., 2003, p. 462). However, it should be stressed that the "higher" cultural levels often highlighted by researchers (Erez and Gati, 2004) may differ between their actual content and how they are perceived, which can be observed through mass creators of culture, obscuring the explanatory potential of those "higher" levels.

The difference between the value-based (and other reified) and activity-based concept of a group (community) culture may be described in a metaphor: according to the former, a group culture is an intersection of individual cultural activities (practices, including semiotic ones), whereas according to the latter, it is their union, including all of the "higher" constructs possessed by and exchanged between individuals. Because a consensus (as an intersection) can be established with respect to a relatively small number of values and other constructs (Wan et al., 2010), culture as a consensus presents a very "poor" description of the diverse values and other constructs of individuals "belonging" to the same culture. According to Kemmelmeier and Kühnen (2012, p. 171), the "temptation is strong to treat culture and cultural differences as a 'thing'. However, research in cultural social psychology and related disciplines has demonstrated that culture is better thought of as a process."

The interpretation of culture as an aggregate of values and practices and their underlying constructs (and other information) faces the problem of separating culture (and cultural practices) from other branches of societal life, e.g., the economy. One of the traditional answers to this challenge was formulated by Clifford Geertz (1973, p. 14; quote from Schudson, 1989, p. 153): "culture is not a power, something to which social events, behaviors, institutions, or processes can be causally attributed; it is a context, something within which they can be intelligibly - that is, thickly - described." Building upon this idea, Michael Schudson (1989, p. 153) himself wrote: "the question of the 'impact' of culture is not answerable because culture is not separable from social structure, economics, politics, and other features of human activity." Evidently, these evaluations refer to culture as a certain whole rather than its individual phenomena or components.

In our opinion, cultural practices can be separated from other practices. This separation is justified by so-called cultural universals, i.e., types of actions present in all human communities that ensure that the basic function of culture is to adapt these communities to the changing environment and ensure their survival (Murdock, 1945; Brown, 1991; Buss, 2001 et al.). Cultural universals (the list of which may vary) are related to culture as aggregates of non-genetically predetermined types of behavior, whereas the ways and forms of realizing cultural universals, i.e., different practices adopted by a community, represent the proper cultures of those communities. In other words, the cultures of communities (including national cultures) are identified through their non-functional qualities and are distinctive in their characteristics, which are insignificant for the functioning of human culture as a whole, i.e., adaptation to the external environment. For example, this approach is fully consistent with practical research in archeology, where cultures are distinguished according to their non-functional qualities, i.e., ornaments on pottery, hatchwork on stone tools, etc. 
In general, the process-based concept of culture sees it as an evolving "constellation of loosely organized ideas and practices that are shared (albeit imperfectly) among a collection of interdependent individuals and transmitted across generations for the purpose of coordinating individual goal pursuits in collective living" (Chiu et al., 2011, p. 4). Obviously, this concept automatically solves the problem of measuring reified culture because there is no reification.

In this case, how can the phenomenon of culture be integrated into economic research? We believe that an alternative to the now dominant approach can be found in a "case-by-case" analysis of the effect of cultural phenomena (in relation to popular cultural practices) on economic processes. An example is presented in research on the economic consequences of the "lobolo" custom, common in South Africa (Ansell, 2001). The custom requires that the bride's family be paid considerable sums, whether in money or in kind, similar to the custom called "kalym," which is widespread in Turkic communities. This type of analysis, while being quite positive, also provides a basis for regulatory recommendations, depending on the total costs and benefits for all of the stakeholders.

Similar examples can be found in abundance, but the one above illustrates the substance of the suggested approach quite well: in analyzing the effects of cultural phenomena on the economy, the focus should first of all be (relatively) popular cultural practices, i.e., those popular in a particular group of individuals such as hired workers, small businessmen, regional politicians, etc.

\section{Conclusion}

As Thomas Friedman commented on relations between the economy and culture, "to reduce a country's economic performance to culture alone is ridiculous, but to analyze a country's economic performance without reference to culture is equally ridiculous, although that is what many economists and political scientists want to do" (Friedman, 2007, p. 562). The problem is how culture should be integrated into economic analysis. This article has the objective of demonstrating that the explanations of macro, meso and micro characteristics of economies based on the fiction of reified societal culture manifested in a "culture code" are, at the very least, unproductive (unless we use Friedman's evaluation "ridiculous").

A more productive way to study the phenomenon of culture is on a "case-bycase," "institution-by-institution" basis, evaluating the impact of each particular cultural phenomenon on economic processes rather than their aggregate because all available "aggregate" dimensions are structured in a way that does not allow the separation of cultural influences from that of formal institutions (from values to trust). Accordingly, one cannot speak about measuring a whole culture, rather than an aggregate institutional environment, without finding a convincing way to separate one from the other, which is usually impossible. Thus, we can say that establishing an econometric relationship between any parameters of a societal culture and particular macroeconomic variables signifies a problem that should be scrutinized through microeconomic research to identify which cultural phenomena cause macroeconomic consequences and what mechanisms are used in the process.

Of course, a component-by-component, case-by-case analysis of the effect of cultural phenomena on the economy will not lead to great discoveries (such as "culture rules" or that "the culture code gets in the way of modernization"), 
though it does provide excellent opportunities for a positive empirical analysis of the ways particular traits of human nature affect various economic processes at various levels across the scale, from micro to macro.

\section{References}

Alesina, A., \& Giuliano, P. (2014). Culture and institutions. Unpublished manuscript.

Ansell, N. (2001). "Because it's our culture!" (Re)negotiating the meaning of lobola in Southern African secondary schools. Journal of Southern African Studies, 27 (4), 697-716.

Auzan, A. A., Arhangelskiy, A. N., Lungin, P. S., \& Nayshul, V. A. (2011). Cultural factors of modernization. Moscow, St. Petersburg: Fondation "Strategiya 2020" (In Russian).

Bandura, A. (1977). Self-efficacy: toward a unifying theory of behavioral change. Psychological Review, 84 (2), 191-215.

Bessonova, O. E. (2007). Phenomenon of the "institutional matrixes theory": Restoration of the outof-date paradigm.. Ekonomicheskaya Nauka Sovremennoy Rossii, 2, 23-33. (In Russian).

Beugelsdijk, S. (2006). A note on the theory and measurement of trust in explaining differences in economic growth. Cambridge Journal of Economics, 30 (3), 371-387.

Beugelsdijk, S., \& Smeets, R. (2008). Entrepreneurial culture and economic growth. American Journal of Economics and Sociology, 67 (5), 915-939.

Brewer, P., \& Venaik, S. (2014). The ecological fallacy in national culture research. Organization Studies, 35 (7), 1063-1086.

Brown, D. E. 1991. Human universals. N. Y.: McGraw-Hill.

Bryson, J. J. (2009). Representations underlying social learning and cultural evolution. Interaction Studies, 10 (1), 77-100.

Buckholtz, J.W., \& Marois, R. (2012). The roots of modern justice: Cognitive and neural foundations of social norms and their enforcement. Nature neuroscience, 15 (5), 655-661.

Bueger, C. (2014). Pathways to practice: Praxiography and international politics. European Political Science Review, 6 (3), 383-406.

Buss, D. M. (2001). Human nature and culture: An evolutionary psychological perspective. Journal of Personality, 69 (6), 955-978.

Chaves, M. (2010). Rain dances in the dry season: Overcoming the religious congruence fallacy. Journal for the Scientific Study of Religion, 49 (1), 1-14.

Chiu, C.-Y., Gelfand, M. J., Yamagishi, T., Shteynberg, G., \& Wan, C. (2010). Intersubjective culture: The role of intersubjective perceptions in cross-cultural research. Perspectives on Psychological Science, 5 (4), 482-493.

Chiu, C.-Y., Leung, A. K.-Y., \& Hong, Y.-Y. (2011). Cultural processes: An overview. In A. K.-Y. Leung, C.-Y. Chiu, \& Y.-Y. Hong (Eds.), Cultural processes: A social psychological perspective (pp. 3-22). N. Y.: Cambridge University Press.

Cialdini, R. B., Kallgren, C. A. \& Reno, R. R. (1990). A focus theory of normative conduct: Recycling the concept. Journal of Personality and Social Psychology, 58 (6), 1015-1026.

Cohen, D. (2001). Cultural variation: Considerations and implications. Psychological Bulletin, 127 (4), 451-471.

Cole, W. M. (2013). Does respect for human rights vary across 'civilizations'? A statistical reexamination. International Journal of Comparative Sociology, 54 (4), 345-381.

Crossland, C. \& Hambrick, D. C. (2011). Differences in managerial discretion across countries: how nation-level institutions affect the degree to which CEOs matter. Strategic Management Journal, 32 (8), 797-819.

Finmarket (2012). Cultural code hinders Russian modernization. URL http://www.finmarket.ru/ main/article/3033422 (In Russian).

Dahl, Ø. (2014). Is culture something we have or something we do? From descriptive essentialist to dynamic intercultural constructivist communication. Journal of Intercultural Communication [On-line serial], 36. URL http://www.immi.se/intercultural/nr36/dahl.html

Dickson, M. W., Castaño, N., Magomaeva, A., \& Den Hartog, D. N. (2012). Conceptualizing leadership across cultures. Journal of World Business, 47 (4), 483-492. 
Drnáková, L. (2006). Cultural values in transition environment - assessment based on International Social Survey Programme Data. CERGE-EI Discussion Paper, 2006-159. Prague: Centre for Economic Research and Graduate Education, Charles University.

Edwards, M. S., \& Patterson, D. (2009). The influence of cultural values on economic growth: An expanded empirical investigation. Journal of Political Science, 37 (1), 148-73.

Enfield, N. J. (2000). The theory of cultural logic: How individuals combine social intelligence with semiotics to create and maintain cultural meaning. Cultural Dynamics, 12 (1), 35-64.

Erez, M., \& Gati, E. (2004). A dynamic, multi-level model of culture: From the micro level of the individual to the macro level of a global culture. Applied Psychology, 53 (4), 583-598.

Fais, O. D. (2003). Modernization at Sardinia and ethno-cultural transformations). Moscow: RUDN Publ. (In Russian).

Fischer, R. (2006). Congruence and functions of personal and cultural values: Do my values reflect my culture's values? Personality and Social Psychology Bulletin, 32 (11), 1419-1431.

Fischer, R. (2012). Intersubjective culture: Indeed intersubjective or yet another form of subjective assessment? Swiss Journal of Psychology, 71 (1), 13-20.

Fischer, R., Ferreira, M. C., Assmar, E., Redford, P., Harb, C., Glazer, S., Cheng, B. S., Jiang, D. Y., Wong, C., Kumar, N., Kaertner, J., Hofer, J., \& Achoui, M. (2009). Individualism-collectivism as descriptive norms: Development of a subjective norm approach to culture measurement. Journal of Cross-Cultural Psychology, 40 (2), 187-213.

Fischer, R. \& Schwartz, S. (2011) Whence differences in value priorities? Individual, cultural, or artifactual sources. Journal of Cross-Cultural Psychology, 42 (7), 1127-1144.

Friedman, T. L. (2007). The world is flat 3.0: A brief history of the twenty-first century. N. Y.: Picador.

Geertz, C. (1973). The interpretation of cultures. N. Y.: Basic Books.

Gelfand, M. J., Nishii, L. H., \& Raver, J. L. (2006). On the nature and importance of cultural tightness-looseness. Journal of Applied Psychology, 91 (6), 1225-1244.

Gerhart, B. (2008a). Cross cultural management research: Assumptions, evidence, and suggested directions. International Journal of Cross Cultural Management, 8 (3), 259-274.

Gerhart, B. (2008b). How much does national culture constrain organizational culture? Management and Organization Review, 5 (2), 241-259.

Granato, J., Inglehart, R., \& Leblang, D. (1996). The effect of cultural values on economic development: Theory, hypotheses, and some empirical tests. American Journal of Political Science, 40 (3), 607-631.

Green, E. G. T., Deschamps, J.-C., \& Páez, D. (2005). Variation of Individualism and Collectivism within and between 20 Countries: A Typological Analysis. Journal of Cross-Cultural Psychology, 36 (3), 321-339.

Greenfield, P. M., Keller, H., Fuligni, A., \& Maynard A. (2003). Cultural pathways through universal development. Annual Review of Psychology, 54 (1), 461-490.

Gusarova, Yu. (2015). Andrey Konchalovskiy vs Aleksandr Auzan: Russians don't want to be wealthy. Snob [Discussion]. URL http://snob.ru/selected/entry/88524

Hanson, J. K. (2009). Cultural values and economic growth: A new look at past findings. Paper presented at the annual meeting of the Midwest Political Science Association, Palmer House Hilton, Chicago, IL, April 2-5.

Helwig, C. C. (2006). The development of personal autonomy throughout cultures. Cognitive Development, 21 (4), 458-473.

Herreros, F. (2012). The state counts: State efficacy and the development of trust. Rationality and Society, 24 (4), 483-509.

Hofstede, G. \& Hofstede, G. J. (2005). Cultures and organizations: Software of the mind (Rev. and expanded 2nd ed.). N. Y.: McGraw-Hill.

Hofstede, G. (1980). Culture's consequences: International differences in work-related values. Beverly Hills: Sage.

Hofstede, G. (1991). Cultures and organizations: Software of the mind. London: McGraw-Hill.

Hofstede, G. (2001). Culture's consequences: Comparing values, behaviors, institutions, and organizations across nations (2nd ed.). Thousand Oaks: Sage.

Hofstede, G. (2002). Dimensions do not exist-A reply to Brendan McSweeney. Human Relations, $55(11), 1355-1361$. 
House, R. J., Javidan, M., \& Dorfman, P. (2001). The GLOBE project. Applied Psychology: An International Review, 50 (4), 489-505.

Huntington, S. P. (1993). The clash of civilizations? Foreign Affairs, 72 (3), 22-49.

Inglehart, R., \& Welzel, C. (2006). Modernization, cultural change and democracy: The human development sequence. N.Y.: Cambridge University Press.

Inglehart, R., Basanez, M., Deiz-Medrano J., Halman L., \& Luijkx, R. (Eds.) (2004). Human beliefs and values: A cross-cultural sourcebook based on the 1999-2002 values surveys. Mexico City: Siglo XXI.

Kapas, J. (2014). How culture matters: the impact of individual values on development. International Institute of Social and Economic Sciences. Paper presented at 14th International Academic Conference, Malta, October 28.

Kemmelmeier, M., \& Kühnen, U. (2012). Culture as process: the dynamics of cultural stability and change. Social Psychology, 43 (4), 171-173.

Kitayama, S. (2002). Culture and basic psychological processes — toward a system view of culture: Comment on Oyserman et al. (2002). Psychological Bulletin, 128 (1), 89-96.

Krasnykh, V. V. (2002). Ethno-linguistics and cultural linguistics. Moscow: Gnozis (In Russian).

Kravchenko, A.I. (2000). Culturology: Dictionary. Moscow: Akademicheskiy proekt (In Russian).

Kroeber, A. L. (1917). The superorganic. American Anthropologist, 19 (2), 163-213.

Kroeber, A. L., \& Kluckhohn, C. (1952). Culture: A critical review of concepts and definitions. Papers of the Peabody Museum of Archaeology and Ethnology, Harvard University, 47 (1).

Kurman, J. (2011). What I do and what I think they would do: Social axioms and behavior. European Journal of Personality, 25 (6), 410-423.

LaPiere, R. T. (1934). Attitudes vs. actions. Social Forces, 13 (2), 230-237.

Lebedeva, N. M. (2007). Culture and economic development: Is there a linkage? In E. G. Yasin (Ed.), Economic modernization and social development (Vol. 2, pp. 220-231). Moscow: Higher School of Economics Publ. (In Russian).

Lebedeva, N. M., \& Tatarko, A. N. (2009). Culture as factor of social progress. Moscow: Yustitsinform (In Russian).

Leung, K., Bond, M. H., de Carrasquel, S. R., Munoz, C., Hernandez, M., Murakami, F., Yamaguchi, S., Bierbrauer, G., \& Singelis, T. M. (2002). Social axioms: the search for universal dimensions of general beliefs about how the world functions. Journal of Cross-Cultural Psychology, 33 (3), 286-302.

Licht, A. N., Goldschmidt, C., \& Schwartz, S. H. (2007). Culture rules: The foundations of the rule of law and other norms of governance. Journal of Comparative Economics, 35 (4), 659-688.

Malinowski, B. (1926). Crime and custom in savage society. N. Y.: Harcourt Brace.

McClelland, D.C. (1961). The achieving society. Princeton: D. Van Nostrand.

McSweeney, B. (2009). Dynamic diversity: Variety and variation within countries. Organization Studies, 39 (9), 933-957.

Medvedeva, E., \& Medvedev, A. (2010). How did market economy emerge, and is it possible in contemporary Russia. Moscow: M-Studio (In Russian).

Mihet, R. (2012). Effects of culture on firm risk-taking: A cross-country and cross-industry analysis. IMF Working Papers, WP/12/210.

Miller, D. T., \& McFarland, C. (1987). Pluralistic ignorance: When similarity is interpreted as dissimilarity. Journal of Personality and Social Psychology, 53 (2), 298-305.

Moles, A. (1973). Socio-dynamics of culture. Moscow: Progress (In Russian).

Morris, M. W. (2014). Values as the essence of culture: Foundation or fallacy? Journal of CrossCultural Psychology, 45 (1), 14-24.

Murdock, G. P. (1945). The common denominators of culture. In R. Linton (Ed.), The science of man in the world crisis (pp. 123-142). N.Y.: Columbia University Press.

Nifaeva, O., \& Nekhamkin, A. (2013). Russian economy's civilizational model formation: Institutional perspective. Moscow: Nauka (In Russian).

Oyserman, D., Kemmelmeier, M., \& Coon, H. M. (2002). Cultural psychology, a new look: Reply to Bond (2002), Fiske (2002), Kitayama (2002), and Miller (2002). Psychological Bulletin, $128(1), 110-117$.

Oyserman, D., Novin, S., Flinkenflogel, N., \& Krabbendam, L. (2014). Integrating culture-assituated-cognition and neuroscience prediction models. Culture and Brain, 2 (1), 1-26. 
Plaut, V. C., Markus, H. R., Treadway, J. R., \& Fu, A. S. (2012). The cultural construction of self and well-being: A tale of two cities. Personality and Social Psychology Bulletin, 38 (12), $1644-1658$.

Ranganathan, S., Spaiser, V., Mann, R.P., \& Sumpter, D. J. T. (2014). Bayesian dynamical systems modelling in the social sciences. PLOS ONE, 9 (1), e86468. doi:10.1371/journal.pone.0086468.

Rapaille, C. (2006). The culture code: An ingenious way to understand why people around the world live and buy as they do. N.Y.: Broadway Books.

Reckwitz, A. (2002). Toward a theory of social practices: A development in culturalist theorizing. European Journal of Social Theory, 5 (2), 243-263.

Rimal, R. N., \& Real, K. (2003). Understanding the influence of perceived norms on behaviors. Communication Theory, 13 (2), 184-203.

Rizzolatti, G. \& Craighero, L. (2004). The mirror-neuron system. Annual Review of Neuroscience, $27,169-92$.

Robinson, J. A., Acemoglu, D., \& Johnson, S. (2005). Institutions as a fundamental cause of long-run growth. In P. Aghion, \& S. Durlauf (Eds.), Handbook of economic growth (Vol. 1A, pp. 386-472). Amsterdam: Elsevier.

Roccas, S., \& Sagiv, L. (2010). Personal values and behavior: Taking the cultural context into account. Social and Personality Psychology Compass, 4 (1), 30-41.

Rodrik, D., Subramanian, A., \& Trebbi, F. (2004). Institutions rule: The primacy of institutions over geography and integration in economic development. Journal of Economic Growth, $9(2), 131-165$.

Romer, P. M. (1986). Increasing returns and long-run growth. Journal of Political Economy, 94 (5), 1002-1037.

Rothstein, B., \& Stolle, D. (2008). The state and social capital: An institutional theory of generalized trust. Comparative Politics, 40 (4), 441-459.

Różycka-Tran, J., Boski, P., \& Wojciszke, B. (2015). Belief in a zero-sum game as a social axiom: A 37-nation study. Journal of Cross-Cultural Psychology, 46 (4), 525-548.

Sachs, J., \& Warner, A. (1995). Natural resource abundance and economic growth. NBER Working Paper, 5398.

Sawang, S., Oei, T. P. S., \& Goh, Y. W. (2006). Are country and culture values interchangeable? A case example using occupational stress and coping. International Journal of Cross Cultural Management, 6 (2), 205-219.

Schmitt, M. J., Schwartz, S., Steyer, R., \& Schmitt, T. (1993). Measurement models for the Schwartz values inventory. European Journal of Psychological Assessment, 9 (2), 107-121.

Schudson, M. (1989). How culture works: Perspectives from media studies on the efficacy of symbols. Theory and Society, 18 (2), 153-180.

Schwartz, S. H. (2006). A theory of cultural value orientations: Explication and applications. Comparative Sociology, 5 (2-3), 136-182.

Schwartz, S.H. (2009). Causes of culture: National differences in cultural embeddedness. In A. Gari, \& K. Mylonas (Eds.), Quod erat demonstrandum: From Herodotus' ethnographic journeys to cross-cultural research (pp. 1-12). Athens: Pedio Books Publishing.

Schwartz, S. H. (2014). Rethinking the concept and measurement of societal culture in light of empirical findings. Journal of Cross-Cultural Psychology, 45 (1), 5-13.

Schwartz, S. H., \& Sagie, G. (2000). Value consensus and importance: A cross-national study. Journal of Cross-Cultural Psychology, 31 (4), 465-497.

Shteynberg, G., Gelfand, M. J., \& Kim, K. (2009). Peering into the "magnum mysterium" of culture: The explanatory power of descriptive norms. Journal of Cross-Cultural Psychology, 40 (1), 46-69.

Soares, A. M., Farhangmehr, M., \& Shoham, A. (2007). Hofstede's dimensions of culture in international marketing studies. Journal of Business Research, 60 (3), 277-284.

Spaiser, V., Ranganathan, S., Mann, R. P., \& Sumpter, D. J. T. (2014). The dynamics of democracy, development and cultural values. PLoS ONE, 9 (6), e97856. doi:10.1371/journal.pone.0097856.

Sperber, D., \& Hirschfeld, L. A. (2004). The cognitive foundations of cultural stability and diversity. Trends in Cognitive Sciences, 8 (1), 40-46.

Tabellini, G. (2010). Culture and institutions: Economic development in the regions of Europe. Journal of the European Economic Association, 8 (4), 677-716. 
Talhelm, T., Zhang, X., Oishi, S., Shimin, C., Duan, D., Lan, X., \& Kitayama, S. (2014). Large-scale psychological differences within China explained by rice versus wheat agriculture. Science, 344 (6184), 603-608

Taras, V., Kirkman, B. L., \& Steel, P. (2010). Examining the impact of culture's consequences: A threedecade, multilevel, meta-analytic review of Hofstede's cultural value dimensions. Journal of Applied Psychology, 95 (3), 405-439.

Terracciano, A., et al. (2005). National character does not reflect mean personality trait levels in 49 cultures. Science, 310 (5745), 96-100.

Trudolyubov, M. (2013). Culture code: Cryptogram from the center. Vedomosti. September 23 (In Russian).

Tsui, A. S., Nifadkar, S. S., \& Ou, A. Y. (2007). Cross-national, cross-cultural organizational behavior research: Advances, gaps, and recommendations. Journal of Management, 33 (3), 426-478.

Tylor, E. B. (1871). Primitive culture. London: John Murray.

Uz, I. (2015) Do cultures clash? Social Science Information, 54 (1), 78-90.

Verizhnikov, A. (2008). Songs on the main things: "Vladimirskiy bastille" and "White roses" as Russian identity's symbols. Industriya Reklamy, 10, 90-94 (In Russian).

Wan, C., Torelli, C. J., \& Chiu, C. (2010). Intersubjective consensus and the maintenance of normative shared reality. Social Cognition, 28 (3), 422-446.

Williamson, C. R. (2009). Informal institutions rule: Institutional arrangements and economic performance. Public Choice, 139 (3-4), 371-387.

Yasin, E. (2007). Modernization and society. Voprosy Ekonomiki, 5, 4-29 (In Russian).

Yasin, E. G. (2014). Cultural influence on Russian modernization. Paper presented at the XV International conference on economic and social development, Higher School of Economics, Moscow, April 1-4 (In Russian).

Zucker, L. G. (1977). The role of institutionalization in cultural persistence. American Sociological Review, 42 (5), 726-743. 